\title{
Screening of Inhibitory Activity against $\alpha$-Amylase of Fungal Endophytes Isolated from Medicinal Plants in Uzbekistan
}

\author{
D.M. Ruzieva, L.I. Abdulmyanova, G.A. Rasulova, R.S. Sattarova* and T.G. Gulyamova \\ Department of Biochemistry and Biotechnology of Physiologically Active Compounds, \\ Institute of Microbiology of the Academy of Sciences RU, Uzbekistan \\ *Corresponding author
}

\begin{tabular}{|c|c|}
\hline & A B S T R A C T \\
\hline $\begin{array}{l}\text { Endophytic fungi, } \\
\alpha \text {-amylase, } \\
\text { Inhibitory activity, } \\
\text { Bio-active natural } \\
\text { products }\end{array}$ & \multirow{3}{*}{$\begin{array}{l}\text { Diabetes is a common metabolic disorder characterized by abnormally increased } \\
\text { plasma glucose levels. Postprandial hyperglycemia plays an essential role in } \\
\text { development of type } 2 \text { diabetes. Inhibitors of carbohydrate-hydrolyzing enzymes } \\
\text { such as } \alpha \text {-amylase retard the liberation of glucose from dietary complex } \\
\text { carbohydrates and delay the absorption of glucose. The purpose of the study was } \\
\text { to isolate and select } \alpha \text {-amylase inhibitor-producing endophytic fungi from well- } \\
\text { known medicinal plants used in the treatment for diabetes and inhabiting in } \\
\text { Uzbekistan. The obtained data showed that } 100 \text { fungal endophytes isolated from } \\
16 \text { local antidiabetic plants produce metabolites with potent inhibiting activity in } \\
\text { vitro }(60-82 \%) \text { and are expected to be a source for therapeutic agents in treatment } \\
\text { of diabetes. }\end{array}$} \\
\hline Article Info & \\
\hline $\begin{array}{l}\text { Accepted: } \\
\text { 25 March } 2017 \\
\text { Available Online: } \\
10 \text { April } 2017\end{array}$ & \\
\hline
\end{tabular}

\section{Introduction}

Diabetes mellitus (DM) is a metabolic disorder caused by insulin deficiency and/or its action promoting chronic hyperglycemia, dislipidemia and protein metabolism disturbance. Complications of diabetes mellitus include increased risk of cardiovascular disease, retinopathy, nephropathy, neuropathy (Kumar et al., 2012; Laar et al., 2008; Mitra et al., 2012). According to data of World Health Organization currently more than 180 million people worldwide have diabetes and it is likely to double by 2030 (Federation, 2011; Mitra et al., 2012). Despite huge advances in modern medicine, the availability of insulin and synthetic hypoglycemic agents, their inability to restore normoglycemia without side effects necessitating alternative therapy (Fujisawa et al., 2005; Mitra et al., 2012).

One of the treatment strategies of diabetes type 2 is reducing of postprandial blood glucose. This may be caused by delayed absorption of glucose via inhibition of the breakdown of oligo- and polysaccharides to mono- and disaccharides by $\alpha$-amylase and $\alpha$ glucosidase in the intestine (Funke et al., 2006; Kumar et al., 2012; Laar et al., 2008; Mentreddy et al., 2007; Sales et al., 2012). Well-known inhibitors of these enzymes such as acarbose and voglibose prolong the total time of digestion of carbohydrates, which delay absorption of glucose with subsequent prevention from postprandial hyperglycemia. 
However, these inhibitors have serious side effects - abdominal pain, bloating, diarrhea, kidney cancer, liver damage and acute hepatitis (Fujisawa et al., 2005; Laar et al., 2008). In this regard, a search of inhibitors of intestinal pancreatic $\alpha$-amylase and $\alpha$ glucosidase, free from major side effects is requested. Studies show that some secondary metabolites of the antidiabetic plants successfully demonstrate the properties of inhibitors of enzymes of carbohydrate degradation, and consequently, may serve to control type 2 diabetes (Bailey et al., 1989; Funke et al., 2006; Kumar et al., 2012; Mentreddy et al., 2007; Sales et al., 2012).

At the same time endophytes inhabiting plants is known as unique class of microorganisms characterized by the production of a large variety of substances contributing to resistance of host plants under various biotic and abiotic stresses. Moreover, they are able to synthesize the characteristic metabolites of the host plants (Gutierrez et al., 2012; Padhi et al., 2013).

Having the ability to synthesize the same secondary metabolites as that of the host plant, endophytes relatively quickly grow on ordinary nutrient media. That's why, currently, endophytes are viewed as an alternative source of useful known and new metabolites including hypoglycemic compounds (Gutierrez et al., 2012; Padhi et al., 2013).

According to the database NAPRALERT (NAtural PRoducts ALERT) and ethnobotanical literature there are about 800 species of antidiabetic plants (Sales et al., 2012; Zubek et al., 2011). many of these plants grow and successfully used in folk medicine of Uzbekistan. In this context the aim of this work was the isolation and study of the endophytes of some antidiabetic plants as potential producers of $\alpha$-amylase inhibitors.

\section{Materials and Methods}

\section{Study area and material sampling}

Plant material was collected in spring 2013 and 2014 on the territory of Tashkent region (Uzbekistan). Plant samples were identified and stored in a herbarium.

\section{Isolation of endophytic fungi}

Endophytic fungi were isolated by the method as described previously by Hazalin et al., (Hazalin et al., 2009). Roots, stems and leaves were respectively washed in tap water, sterilized in $70 \%$ ethanol for 1 min followed by $0.1 \% \mathrm{HgCl}_{2}$ for $7 \mathrm{~min}$, rinsed three times in de-ionized water, cut into segments approximately $5 \mathrm{~mm}$ in diameter and placed in $90 \mathrm{~mm}$ Petri dishes containing Czapek-Dox agarized medium with $50 \mathrm{mg} / \mathrm{ml}$ chlortetracycline and $250 \mathrm{mg} / \mathrm{ml}$ streptomycin sulfate to inhibit bacterial growth. The plates were incubated for 7-14 days at $28{ }^{\circ} \mathrm{C}$. Different mycelia growing out of the segments were sub-cultured and individually maintained on antibiotics-free Czapek-Doxagar medium. Colony morphology and growth and spore formation of the isolates were then studied on Potato-Dextrose-agar medium.

\section{Endophytic fungi identification}

Isolated strains were identified by classical methods on the basis of morphology using pertinent monographs (Litvinov, 1967). Isolated strains were deposited at the Institute of Microbiology of the Uzbekistan Academy of Sciences where they were maintained at +4 ${ }^{\circ} \mathrm{C}$.

\section{Fermentation}

To accumulate biomass for further extraction and determination of biological activity, 
endophytes were grown by submerged fermentation in $500 \mathrm{ml}$ flasks containing 100 $\mathrm{ml}$ of Chapek-Dox liquid medium for 5 days at $26{ }^{\circ} \mathrm{C}$.

\section{The extraction of secondary metabolites of endophytic fungi}

For extraction of secondary metabolites $5 \mathrm{~g}$ of biomass of each isolate was milled in a Potter homogenizer, transferred to a cone flask containing $50 \mathrm{ml}$ of ethyl acetate, and left for 24 hours on the rotary shaker at room temperature. The mixture was filtered through filter paper (Whatman \#1) and $\mathrm{Na}_{2} \mathrm{SO}_{4}(40$ $\mu \mathrm{g} / \mathrm{ml}$ ) was added. After the filtration, the extract was striped to dryness on a rotary evaporator and mixed with $1 \mathrm{ml}$ of dimethyl sulfoxide (DMSO). The resulting extract was used as a stock solution and stored at $4{ }^{\circ} \mathrm{C}$.

\section{Determination of $\alpha$-amylase activity}

Determination of $\alpha$-amylase activity was carried out by the modified method used for measurements in the plant extracts (Picot et al., 2014). For this purpose a solution of starch as a substrate was prepared at the rate of $1 \mathrm{~g} / 10 \mathrm{ml}$ water, boiled for 2 minutes, adjusted to $100 \mathrm{ml}$ with distilled water and used within 2 - 3days. To $2 \mathrm{ml}$ of the prepared starch solution $100 \mu \mathrm{l}$ pancreatic $\alpha$-amylase (13 $\mathrm{u} / \mathrm{ml}$ in $0.1 \mathrm{M} \mathrm{Na}$-acetate buffer $\mathrm{pH} 4,7)$, $100 \mu \mathrm{l}$ of the extract endophyte $(20 \mathrm{mg} / \mathrm{ml}), 2$ $\mathrm{ml}$ of acetate buffer were added and incubated for 10 minutes at $30^{\circ} \mathrm{C}$. In contrast to the test sample the extract was not added to a control . After incubation the reaction was terminated by adding $10 \mathrm{ml}$ of iodine reagent and the absorbance was measured on spectrophotometer SPECOL -1300 at a wavelength of $630 \mathrm{~nm}$. For the preparation of iodine reagent $0.5 \mathrm{~g}$ of crystalline iodine, $5 \mathrm{~g}$ of potassium iodide were dissolved in $250 \mathrm{ml}$ of water; to obtain a working solution of $2 \mathrm{ml}$ of this reagent was adjusted to $100 \mathrm{ml}$ by 0.1 M HCL.
All the assays were carried out in triplicates and average percent inhibition of enzymes by the fungal extract was calculated using the following formula:(A0-At)/A0x100\%, where A0 - absorption of control sample, At is the absorption of test sample, respectively.

\section{Results and Discussion}

The study of lipid-lowering and anti-diabetic activity of various fractions of extracts of the mycelium of 17 endophytic fungi isolated from Salvadora oleoides Decne (Salvadoraceae) showed that the extracts of two endophytic fungi pp. Aspergillus and Phoma significantly decrease blood glucose level (Dhankhar et al., 2013). It was found that the basic substance of these active extracts are presented by phenolic compounds. It was also shown that all investigated extracts are safe and have no lethal effect on animals at doses up to 1000 $\mathrm{mg} / \mathrm{kg}$ of body weight, and safe dose for human erythrocytes is up to $500 \mu \mathrm{g} / \mathrm{ml}$. Positively active as inhibitors of $\alpha$ - amylase and $\alpha$-glucosidase were extracts of 9 from 22 fungal endophytes isolated from the Indian anti-diabetic plants Momordica charantia and Trigonella foenum-graceum. In the experimental conditions in vitro IC50 of two isolates were lower than the control acarbose. The active strains were identified as Trichoderma atroviride and Stemphylium globuliferum (Pavithra et al., 2014).

According to research of antidiabetic activity of Syncephalastrum racemosum, isolated from red algae Gracilaria corticata, its acetone and methanol extracts inhibited amylase activity up to 19,4 and $23.7 \%$, respectively (Ushari et al., 2015).

From the roots, stems and leaves of 16 plants growing in Uzbekistan, we obtained 100 endophytic fungal isolates related to Acremonium, Alternaria, Aspergillus, 
Gliocladium, Fusarium, Penicillium, pancreatic $\alpha$-amylase and starch as a Trichoderma and Ulocladium genera. substrate, the concentration of the extracts Antidiabetic properties of their ethyl acetate was $100 \mu \mathrm{g} / \mathrm{ml}$.

extracts were carried out in vitro with using

Table.1 $\alpha$-Amylase inhibition activity of isolated endophytes

\begin{tabular}{|l|l|l|}
\hline$\#$ & Endophyte & $\%$ inhibition \\
\hline 1 & Alternaria sp. - VE98L & 60,0 \\
\hline 2 & Aspergillusterreus - AF104S & 60,0 \\
\hline 3 & Penicillium sp. - AF106 & 60,0 \\
\hline 4 & Mycelia sterilia - MO46L & 62,0 \\
\hline 5 & Eupinicilliumbrefeldianum - VE97R & 62,5 \\
\hline 6 & Aspergillusterreus - FS114 & 64,0 \\
\hline 7 & Acremoniumroseum - HT164S & 64,0 \\
\hline 8 & Aspergillusflavus - HP131L & 66,0 \\
\hline 9 & Penicillium sp. - AF120 & 70,0 \\
\hline 10 & Aspergillusterreus - 138 & 76,05 \\
\hline 11 & Aspergillus sp. - HT162S & 81,0 \\
\hline 12 & Penicillium sp. - HT165S & 81,0 \\
\hline 13 & Aspergillusegypticus - HT166S & 82,0 \\
\hline 14 & Aspergillusterreus -CM40L & 82,0 \\
\hline
\end{tabular}

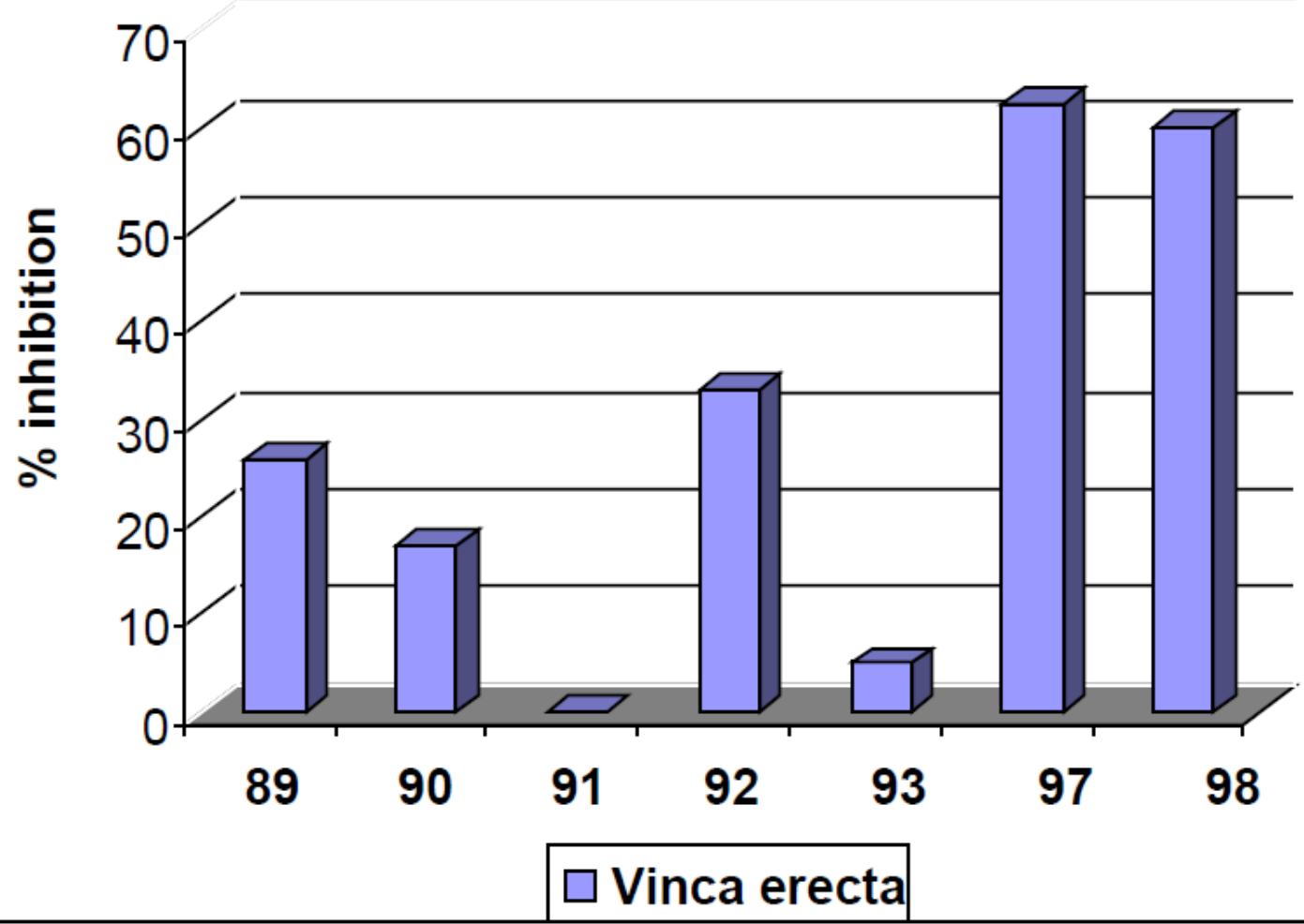



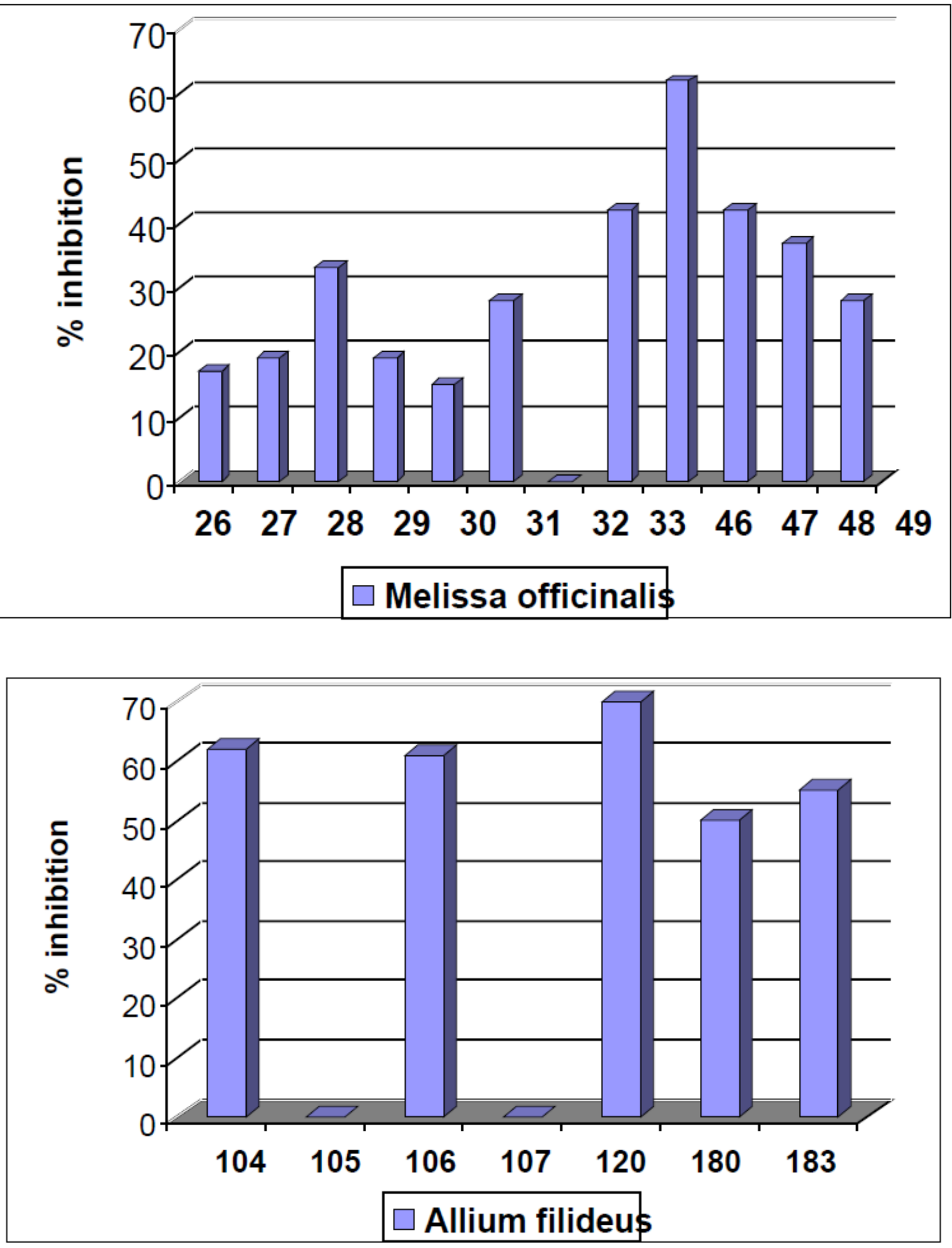

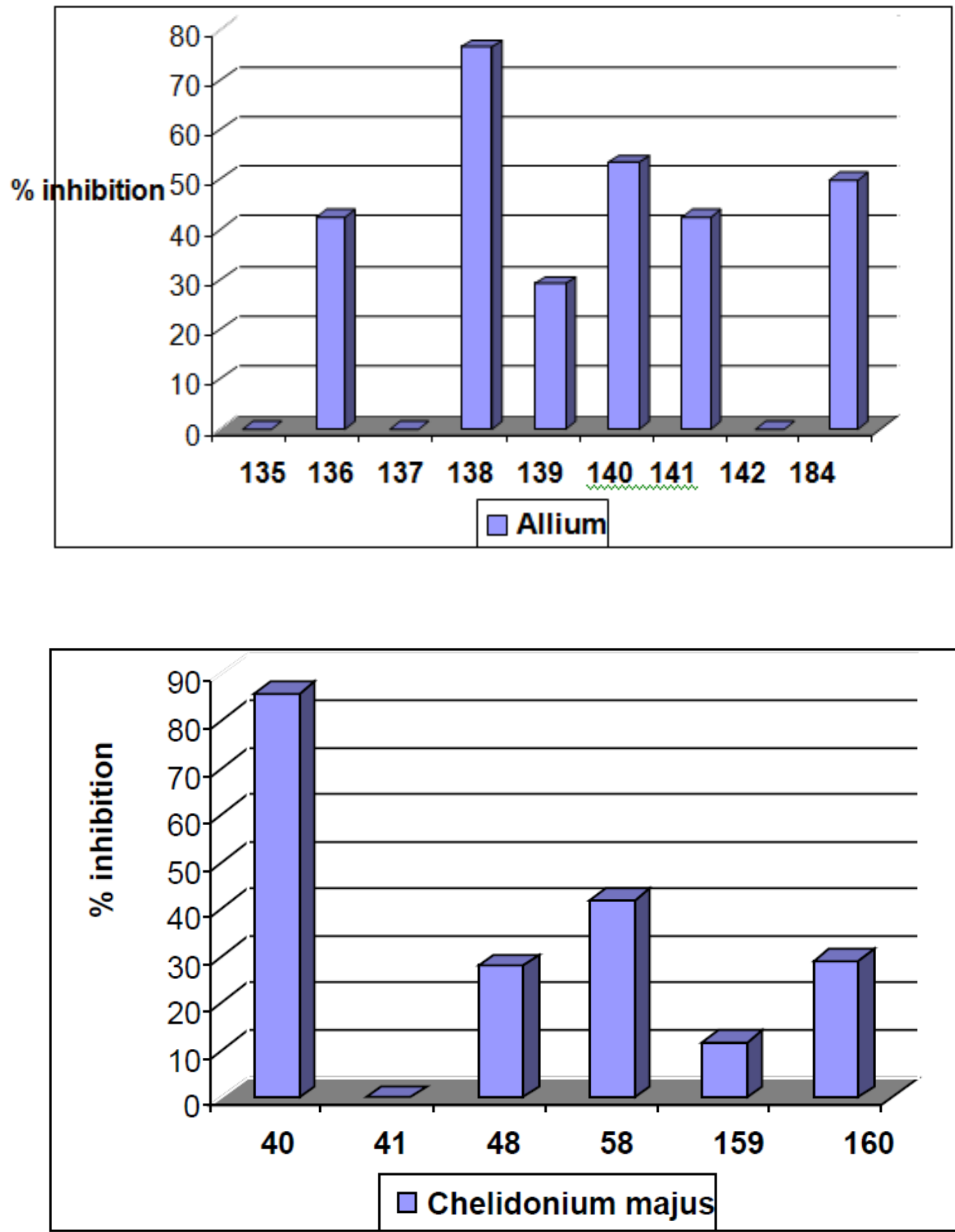


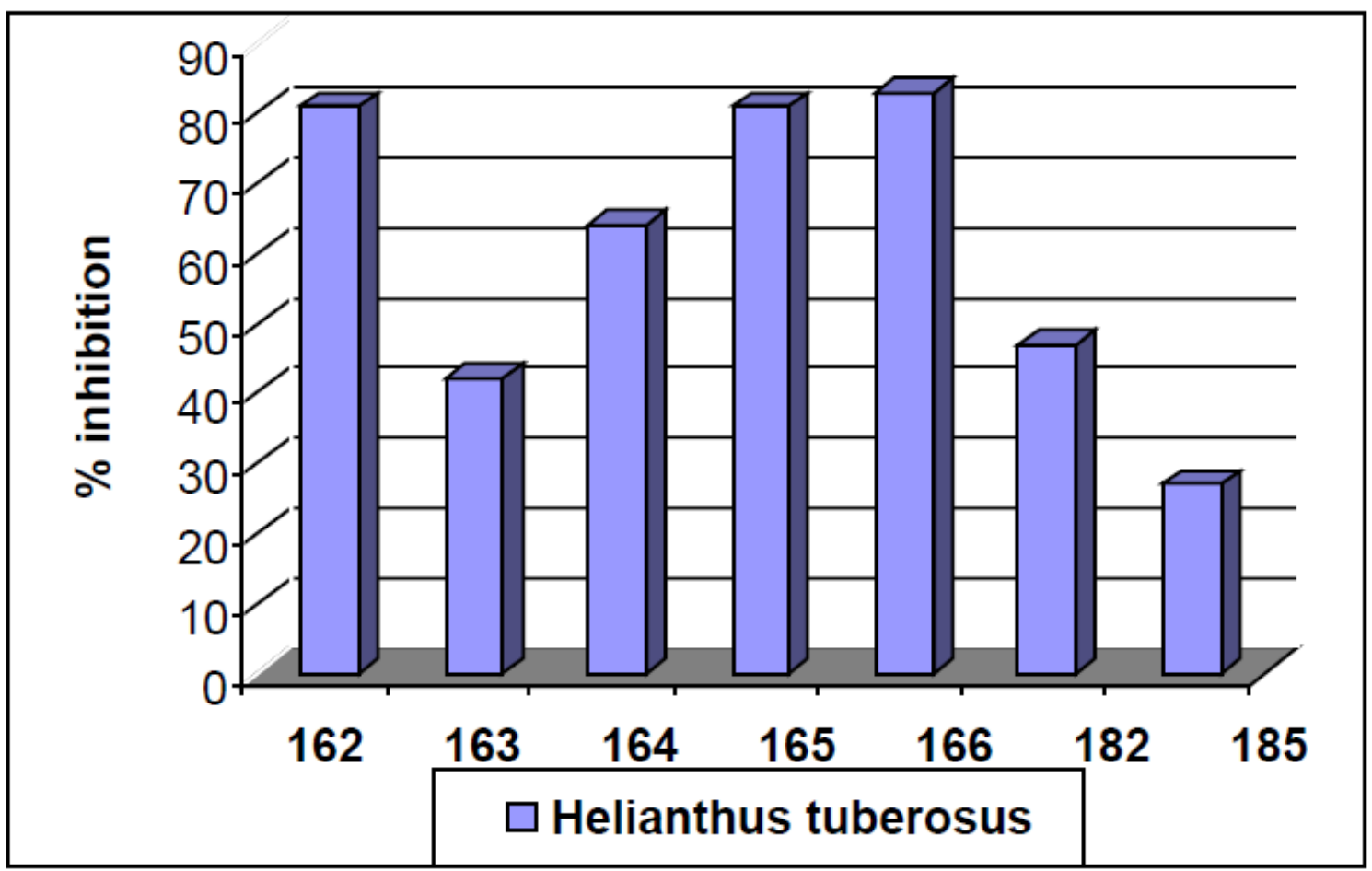

Fig.1 Inhibitory activity of fungal endophytes

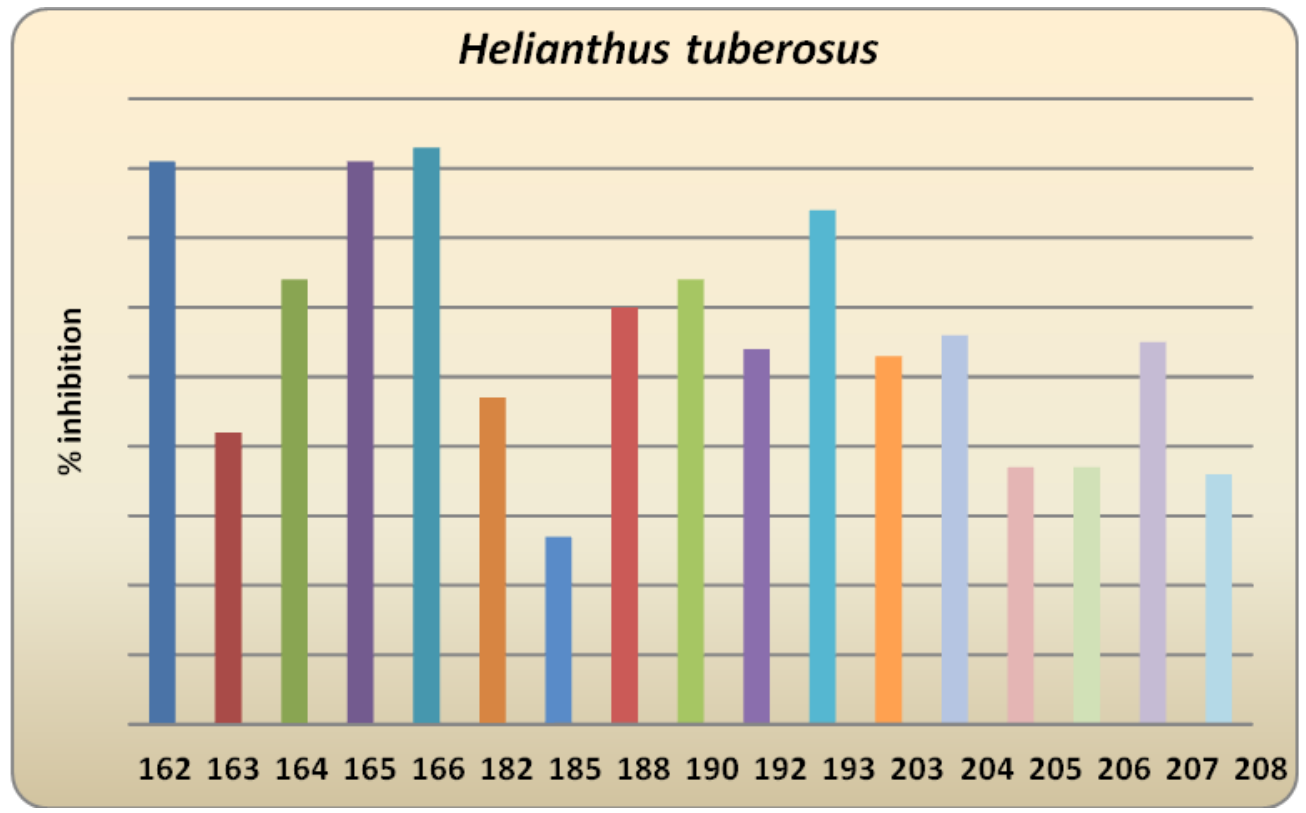

The results of this experiment showed the presence of inhibitory activity in $67 \%$ of studied endophytes. The low activity (20$40 \%$ ) showed $27 \%$ of strains, medium (40$60 \%$ ) $-28 \%$, and only $15 \%$ inhibited the activity of $\alpha$-amylase by more than $60 \%$.
Thus, endophytic fungi isolated from Ocimum basilicum, Ephedra strobiaceae, Eremurus, Crocus sativus, Lagochilus olga, Peganum harmala, Vinca rosea showed low inhibitory activity. It should be noted that the distribution and the magnitude of the 
inhibitory activity of endophytic fungi are quite different even within a single host plant (Figure 1.).

For example, the most endophytes selected from two kinds of periwinkle (Vinca minor and Vinca erecta) inhibit the action of the enzyme but a high activity is shown only by two strains: Alternaria sp. - VE98L $(60 \%)$ and Eupinicillium brefeldianum - VE97R (62,5\%). Three selected fungal isolates of peppermint (Mentha piperita) show the inhibition of $\alpha$ amylase in the range of $46-50 \%$. In 11 out of 12 fungi isolated from different organs of balm (Melissa officinalis) it is observed inhibitory activity from 19 to $62 \%$. The highest inhibitory activity detected in a strain Mycelia sterilia - MO46L (62\%).

High activity of inhibition of the enzyme was found in 3 of the 6 extracts of endophytic fungi from bulbs of Allium filideus: Aspergillus terreus - AF104S (62\%), Penicillium sp. - AF106 (61\%) and Penicillium sp. - AF120 (70\%). In the other plant of the genus Allium longicuspis highest inhibitory activity at the level of $76.5 \%$ exhibited by endophyte Aspergillus terreus 138. Among endophytes of endemic plants Haloxylon persicum and Ferula sumbul only one strain inhibited alpha-amylase by $66 \%$ (Aspergillus flavus - HP131L) and 64\% (Aspergillus terreus - FS114), respectively.

Finally, the highest inhibitory effect on $\alpha$ amylase activity showed three strains isolated from Helianthus tuberosus: Aspergillus sp. HT162S (81\%), Penicillium sp. - HT165S (81\%), Aspergillus egypticus - HT166S (82\%), one strain isolated from Chelidonium majus - Aspergillus terreus - CM40L (82\%), and one strain isolated from Celosia cristata Penicillium sp.- CC200 (80\%).

It should be noted that acarbose used as a reference drug, at a concentration of 100 $\mu \mathrm{g} / \mathrm{ml}$, inhibited the enzyme activity by $82 \%$ (Table1).

Analysis of the total data shows that the endophytes related to genus Aspergillus and of Penicillium isolated from the sunflower native plants (Helianthus tuberosus) and (Chelidonium majus) synthesize metabolites which have great inhibition potential against pancreatic $\alpha$-amylase comparable with commercial inhibitor acarbose (over 80\%). Thus, the results of the study are a prerequisite for the study of metabolites of these strains of endophytic fungi as perspective source of new native inhibitors of pancreatic $\alpha$-amylase.

\section{References}

Bailey C.J., Day C. 1989. Traditional plant medicines as treatments for diabetes. Diabetes Care. 12: 553-564.1. Mitra A., Dewanjee D., Dey B. 2012. Mechanistic studies of lifestyle interventions in type 2 diabetes. World J Diabetes, 3: 201-207.

Dhankhar S.1, Dhankhar S., Yadav J.P. 2013. Investigations towards new antidiabetic drugs from fungal endophytes associated with Salvadora oleoides Decne. Med Chem. Jun 1, 9 (4): 624-629.

Federation I.D. 2011.IDF diabetes atlas: International Diabetes Federation, Executive Office.

Fujisawa H.I., K. Inoue, Y. Kawabata and T. Ogihara. 2005. Effect of two alphaglucosidase inhibitors, voglibose and acarbose, on postprandial hyperglycemia correlates with subjective abdominal symptoms. Metabolism., 54: 387-3903.

Funke I., Melzing M.F. 2006. Traditionally used plants in diabetes therapy phytotherapeutics as inhibitors of $\alpha$ amylase activity. Rev Bras 
Farmacogn, 16: 1-5.

Gutierrez R.M.P., Gonzalez A.M.N. and Ramirez A.M. 2012. Compounds Derived from Endophytes: A Review of Phytochemistry and Pharmacology. Curr Med Chem, 19: 2992-3030.

Hazalin N.A., Ramasamy K., Lim S.M., Wahab I.A., Cole A.Lj, Majeed A.A. 2009. Cytotoxic and antibacterial activities of endophytic fungi isolated from plants at the National Park, Pahang, Malaysia. BMC Complementary and alternative medicine, 9: 46.

Kumar S., Kumar V., Rana M., Kumar D. 2012. Enzyme inhibitors from plants: An alternate approach to treat diabetes. Pharmacog Communi, 2: 1833.

Laar F.A., Lucassen PL.BJ., Akkermans R.P., Lisdonk E.H., Rutten GEHM, Weel C. 2008. Alpha-glucosidase inhibitors for type 2 diabetes mellitus (Cochrane Review). The Cochrane Library.

Litvinov M.A. 1967. Identification guide for microscopic fungi. Nauka, Leningrad.

Mentreddy S.R. 2007. Medicinal plant species with potential antidiabetic properties. J. Sci. Food Agric., 87: 743-750.

Mitra A., Dewanjee D., Dey B. Mechanistic studies of lifestyle interventions in type 2 diabetes. 2012. World J Diabetes, 3: 201-207.

Padhi 1., MohandaY.K., Panda S.K. 2013. Endophytic fungi with great promises: A Review J. Adv. Pharm. Edu. \& Res.,
3 (3): 152-170.

Pavithra N., Sathish L., Babu N., Venkatarathanamma V., Pushpalatha H., Reddy G.B., Ananda K. 2014 Evaluation of $\alpha$-amylase, $\alpha$ glucosidase and aldose reductase inhibitors in ethyl acetate extracts of endophytic fungi isolated from antidiabetic medicinal plants. Int. J. Pharm Sci Res, 5 (12): 5334-5341.

Picot C.M.N., Subratty H., Mahomoodally F. 2014 Inhibitory potential of five native antidiabetic medicinal plants on $\alpha$ amylase, $\quad \alpha$-glucosidase, glucose entrapment, and amylosysis kinetics in vitro. Adv.Pharm.Sci, V., 1-7.

Sales P.M., Souza P.M., Simeoni L.A., Magalhres P.O., Silveira D. 2012. $\alpha-$ Amylase Inhibitors: A Review of Raw Material and Isolated Compounds from Plant Source. J. Pharm. Pharmaceut Sci., 15 (1): 141-183.

Ushari R., Anusha R. 2015. In vitro antidiabetic activity of ethanolic and acetone extracts of endophytic fungi Syncephalastrum racemosum isolated from the seaweed Gracilaria corticata by $\alpha$-amylase inhibition assay method .Int. J. Curr. Microbiol. App. Sci., 4 (1): 254-259.9.

Zubek S., Nobis M., Blaszkowski J., Mleczko P., Nowak A. 2011. Fungal root endophyte associations of plants endemic to the Pamir Alay Mountains of Central Asia. Symbiosis, 54: 139149.

\section{How to cite this article:}

Ruzieva, D.M., L.I. Abdulmyanova, G.A. Rasulova, R.S. Sattarova and Gulyamova, T.G. 2017. Screening of Inhibitory Activity against $\alpha$-Amylase of Fungal Endophytes Isolated from Medicinal Plants in Uzbekistan. Int.J.Curr.Microbiol.App.Sci. 6(4): 2744-2752. doi: https://doi.org/10.20546/ijcmas.2017.604.318 